\title{
Nasal high frequency ventilation in neonates with moderate respiratory insufficiency
}

\author{
Mark van der Hoeven, Erik Brouwer, Carlos E Blanco
}

\begin{abstract}
Aim-To investigate the efficacy of nasal high frequency ventilation (nHFV) in newborn infants with moderate respiratory insufficiency.

Method-Twenty one preterm and term neonates were treated with nHFV for respiratory insufficiency. Criteria for starting nHFV were: deterioration on nasal CPAP expressed by a median $\mathrm{pH}$ of 7.24 and $\mathrm{pCO}_{2}$ of $8.3 \mathrm{kPa}$, or increasing $\mathrm{FIO}_{2}$. nHFV was delivered using the Infant Star ventilator. Ventilator setting amplitude was $35 \mathrm{~cm} \mathrm{H}_{2} \mathrm{O}$; mean airway pressure 7 $\mathrm{cm} \mathrm{H}_{2} \mathrm{O}$; and frequency $10 \mathrm{~Hz}$.

Results- $\mathrm{pCO}_{2}$ decreased significantly from $8.3 \mathrm{kPa}$ to $7.2 \mathrm{kPa}$ after $\mathrm{nHFV}$ was started. In five patients nHFV was discontinued after a median period of $61 / 2$ hours due to $\mathrm{CO}_{2}$ retention and high oxygen need, and endotracheal mechanical ventilation was started.

Conclusions-nHFV can reduce $\mathrm{pCO}_{2}$ in neonates with moderate respiratory insufficiency and, therefore, could be used to decrease the need for endotracheal mechanical ventilation.

(Arch Dis Child Fetal Neonatal Ed 1998;79:F61-F63)
\end{abstract}

Keywords: nasal high frequency ventilation; idiopathic respiratory distress syndrome

Over the past two decades assisted mechanical ventilation has been used to manage respiratory insufficiency in newborn infants. However, complications such as airleaks occur in 15 to $48 \%$ of the infants who need ventilator support, ${ }^{12}$ and 5 to $25 \%$ develop bronchopulmonary dysplasia (BPD). ${ }^{3}$ Both these complications contribute substantially to morbidity in preterm infants. Therefore, a less invasive approach such as nasal continuous positive airway pressure (nCPAP) is frequently used in the initial management of respiratory insufficiency. ${ }^{4-6}$ But 43 to $80 \%$ of the neonates with moderate to severe respiratory insufficiency, initially treated with nasal CPAP, will
Table 1 Summary of clinical data of 21 infants studied

\begin{tabular}{lc}
\hline & $\begin{array}{l}\text { Median } \\
\text { (20th-80th percentile) }\end{array}$ \\
\hline Birthweight (g) & $1010(750-2170)$ \\
Gestation (weeks) & $29(27-32)$ \\
Age at study (h) & $24(4-480)$ \\
Duration nHFV (h) & $36(12-108)$ \\
IRDS & 10 \\
TTN & 3 \\
Air leak & 2 \\
Apnoea & 6 \\
Required mechanical ventilation & 5 \\
\hline
\end{tabular}

IRDS: idiopathic respiratory distress syndrome; TTN: transient tachypnoea of the newborn

need subsequent mechanical ventilation. ${ }^{7}$ Nasal CPAP has also been used after extubation to facilitate weaning from mechanical ventilation. ${ }^{8-11}$ However, extubation failed in 16 to $40 \%$ of cases. In both events subsequent endotracheal mechanical ventilation was needed because of $\mathrm{CO}_{2}$ retention or increased oxygen need and apnoea of prematurity.

High frequency ventilation (HFV) is a new method of mechanical ventilation based on the delivery of small tidal volumes at a supraphysiological respiratory frequency of $10 \mathrm{~Hz}^{12}{ }^{13}$ This technique is very effective in eliminating carbon dioxide and is independent of dead space.

We hypothesised that HFV applied on a single nasopharyngeal tube (nHFV) might reduce $\mathrm{pCO}_{2}$ by augmenting $\mathrm{CO}_{2}$ diffusion in the pharynx and larynx area and, therefore, decreasing the need for subsequent mechanical ventilation. To test this hypothesis we performed a non-controlled observational study and tested the efficacy of nHFV in infants with moderate respiratory insufficiency.

\section{Methods}

Twenty one newborn infants were offered nHFV. All patients were initially treated with nasal CPAP applied via a single nasopharyngeal tube positioned at a depth of $3-4 \mathrm{~cm}$. nHFV was started due to $\mathrm{CO}_{2}$ retention (median value $8.3 \mathrm{kPa}$ ), acidosis (median $\mathrm{pH}$ value 7.24), and/or increasing oxygen need

Table 2 Values (median with 20th and 80th percentiles) of blood gases and ventilator settings before and after initiation of nHFV

\begin{tabular}{|c|c|c|c|c|c|c|}
\hline & \multicolumn{2}{|l|}{ Before } & \multicolumn{4}{|l|}{ After } \\
\hline & $n=19$ & $n=21$ & $n=21$ & $n=14$ & $n=15$ & $n=15$ \\
\hline Time (h) & $-4.15^{\prime}\left(-6.25^{\prime}--3.28^{\prime}\right)$ & $-0.57^{\prime}\left(-1.57^{\prime}--0.34^{\prime}\right)$ & $1.30^{\prime}\left(0.50^{\prime}-2.00^{\prime}\right)$ & $4.24^{\prime}\left(3.20^{\prime}-5.20^{\prime}\right)$ & $7.38^{\prime}\left(6.52^{\prime}-8.00^{\prime}\right)$ & $11^{\prime}\left(10.00^{\prime}-13.00^{\prime}\right)$ \\
\hline $\mathrm{pH}$ & $7.24(7.20-7.28)$ & $7.24(7.19-7.29)$ & $7.26(7.24-7.32)$ & $7.28(7.24-7.32)$ & $7.31(7.24-7.42)$ & $7.31(7.27-7.36)$ \\
\hline $\mathrm{pCO}_{2}(\mathrm{kPa})$ & $8.0(7.3-8.9)$ & $8.3(7.4-9.1)$ & $7.2(6.6-8.3)^{\star}$ & $7.1(6.5-7.9)^{\star}$ & $6.5(5.7-7.9)$ & $6.7(5.9-7.4) 9$ \\
\hline $\mathrm{Paw}\left(\mathrm{cm} \mathrm{H}_{2} \mathrm{O}\right)$ & $5(5-6)$ & $6(5-7)$ & $7(6-8.6) \S$ & $7(6-8) \int$ & $7(6-8) \subseteq$ & $7(6-8) \subseteq$ \\
\hline Amplitude $\left(\mathrm{cm} \mathrm{H}_{2} \mathrm{O}\right)$ & & & $37(29-46)$ & $35(28-47)$ & $35(29-47)$ & $35(28-48)$ \\
\hline $\mathrm{FIO}_{2}$ & $0.35(0.21-0.5)$ & $0.42(0.21-0.60)$ & $0.40(0.21-0.60)$ & $0.40(0.21-0.50)$ & $0.37(0.21-0.51)$ & $0.32(0.21-0.51)$ \\
\hline
\end{tabular}

${ }^{\star} \mathrm{pCO}_{2}$ was significantly different (Wilcoxon $\mathrm{p}<0.005$ ) from $\mathrm{pCO}_{2}$ in the two blood gases registered before nHFV was initiated. IpCO ${ }_{2}$ was significantly different (Wilcoxon $\mathrm{p}<0.01$ ) from $\mathrm{pCO}_{2}$ in the two blood gases registered before nHFV. §Pāw settings after the start of nHFV were significantly different (Wilcoxon p<0.01) from each of the two Pāw pressure values registered before nHFV was initiated. 


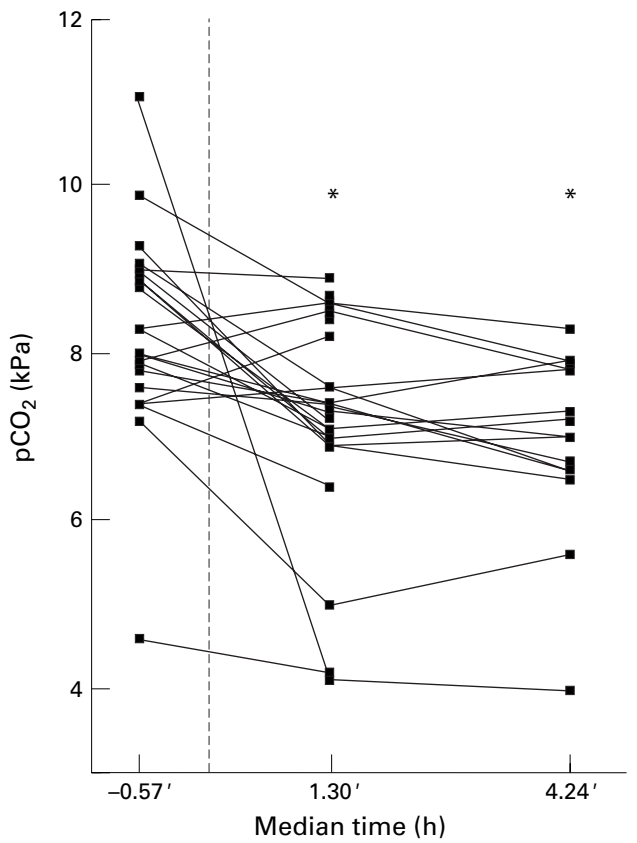

Figure 1 Course of $\mathrm{PCO}_{2}$ in blood gas before and two blood gases after start of $n \mathrm{HFV} . \mathrm{PCO}_{2}$ decreased significantly in both samples taken at a median time of $11 / 2$ hours (0.50-2) hours and at 4.24 (3.2-5.2) hours after the start of $n H F V$ compared with that in the sample taken at 0.57 (1.57-0.34) hours before $n H F V$ was started. $p=$ 0.0012 and 0.0033 , respectively.

(median $\mathrm{FIO}_{2}$ 0.42) during nasal CPAP. We applied $\mathrm{nHFV}$ via the same nasopharyngeal tube by switching the ventilator (Infant Star $\mathrm{HFV}$, Infrasonics, Inc. San Diego, CA, USA) to the HFV mode. This ventilator delivers HFV by flow interruption. NHFV was initiated with the following parameters: mean airway pressure (Pāw) was maintained or increased to a higher level; frequency of $10 \mathrm{~Hz}$ and amplitude was increased until the infant's chest showed oscillations; $\mathrm{FIO}_{2}$ was regulated to achieve a peripheral oxygen saturation monitored by pulse oximetry of $86-93 \% .^{14-15}$ Arterial or capillary blood gases and ventilator settings were registered at a median time of $4 \frac{1}{4}$ hours (3.286.25 hours) and of 0.57 hours (0.34-1.57

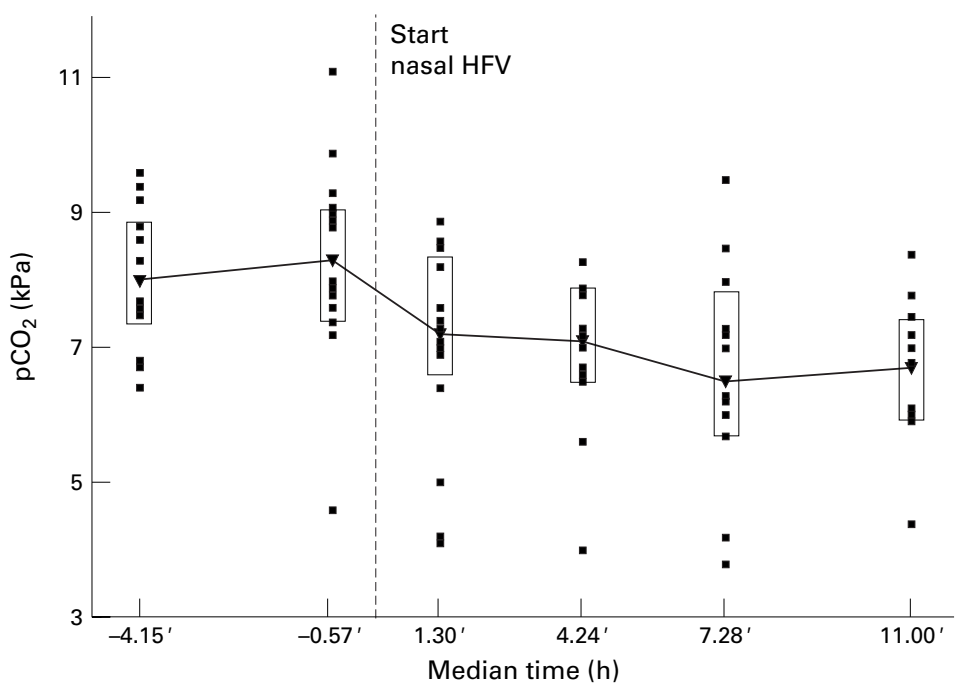

Figure 2 Course of $\mathrm{pCO}_{2}$ in two blood gases measured before (4.15 and 0.57 hours) and four blood gases measured after (1.3, 4.24, 7.38 and 11 hours) the start of nHFV.Median and 20th and 80th percentiles are shown together. hours) before and $1 \frac{1}{2}$ hours (0.50-2 hours), 4.24 hours (3.20-5.20 hours), 7.38 hours (6.52-8 hours), and 11 hours (10-13 hours) after nHFV initiation. Endotracheal mechanical ventilation was considered when blood gases further deteriorated: $\mathrm{pH}<7.20 ; \mathrm{pCO}_{2}>$ $8.5 \mathrm{kPa}$; and $\mathrm{FIO}_{2}>0.80$ or apnoea.

All values are reported as median with 20th and 80th percentiles. A Wilcoxon signed rank sum test for paired data was used to estimate statistical difference for blood gases and ventilator settings. Differences were considered statistical significant when $\mathrm{p}<0.05$.

\section{Results}

Twenty one patients were treated with nHFV. Table 1 summarises the clinical data. In five (23\%) patients, $\mathrm{nHFV}$ was discontinued after a median time of $61 / 2$ hours (2-81/2 hours), and endotracheal mechanical ventilation was started. Table 2 shows blood gas values and ventilator settings before and after initiating nHFV. NHFV was started in 16 infants because of $\mathrm{CO}_{2}$ retention $\left(\mathrm{pCO}_{2}\right.$ value $>7.5$ $\mathrm{kPa})$ and in five infants because of increasing oxygen need $\left(\mathrm{FIO}_{2}>0.55\right)$. A small but significant reduction in $\mathrm{pCO}_{2}$ was found $(\mathrm{p}=0.0012$; $\mathrm{p}=0.0033$ ) after initiation of $\mathrm{nHFV}$ compared with the two last blood gases taken before nHFV (figs 1 and 2). Pāw pressure was significantly higher after the initiation of nHFV.

In $15 / 21(72 \%)$ patients, nHFV was initiated early in the course of their respiratory disease (median age of 17 hours; 2-36). Respiratory insufficiency was due to idiopathic respiratory distress syndrome $(n=10)$, transient tachypnoea of the newborn (TTN) $(\mathrm{n}=3)$, and hypoventilation $(n=2)$. NHFV was continued for a median (range) period of 35 (2-144) hours. In three patients with severe idiopathic RDS, nHFV was discontinued and endotracheal mechanical ventilation with surfactant replacement was started within 2 to 6 hours because of further deterioration in blood gases or increased oxygen need.

In $6 / 21(28 \%)$ patients, nHFV was initiated at a median age 9 days (6-21), after a period of endotracheal mechanical ventilation. The diagnoses included air leak syndrome $(n=2)$ and apnoea associated with sepsis or necrotising enterocolitis $(\mathrm{n}=4)$. NHFV in this group was continued for a median period of 40 hours (17-126). In two patients in this group with apnoea and sepsis, nHFV was discontinued and endotracheal mechanical ventilation was started because of further deterioration in blood gases and apnoea.

\section{Discussion}

This study has shown that $\mathrm{nHFV}$ can reduce $\mathrm{pCO}_{2}$ in patients with nasal CPAP with different respiratory problems. Whether $\mathrm{nHFV}$ can be recommended as a valuable mode of respiratory support must be determined in a prospective randomised study. We showed that nHFV was effective in reducing $\mathrm{pCO}_{2}$ from 8.3 $\mathrm{kPa}$ to $7.2 \mathrm{kPa}$ within 2 hours.

The mechanism of $\mathrm{CO}_{2}$ reduction during $\mathrm{HFV}$ is complex and is not completely understood. ${ }^{1316}$ As oscillations of the chest are 
visible during $\mathrm{nHFV}$, direct ventilation of the lung is less important; the larynges are a significant factor in resistance. ${ }^{17}$ Gas transport during $\mathrm{nHFV}$ is probably largely improved by the interaction of convective and diffusive gas flux (also called augmented diffusion) in the pharyngeal and laryngeal area, as has been reported during $\mathrm{HFV}$ in the larger and medium airways. ${ }^{1618}$

Nasal CPAP has been proposed as a less invasive approach for the management of respiratory distress in very low birthweight infants. $^{4-6}$ After the introduction of nasal CPAP, a significant decrease in the incidence of intubation was reported. ${ }^{19}$ Another report showed that the incidence of BPD was decreased in association with the use of early nasal CPAP and permissive hypercapnia. ${ }^{20}$ However, the use of nasal CPAP seemed to be limited to a small group of infants, as 43 to $80 \%$ of the infants with moderate to severe idiopathic RDS went on to require mechanical ventilation due to $\mathrm{CO}_{2}$ retention, increased oxygen need, and apnoea of prematurity. ${ }^{7}$ The level of CPAP pressure is associated with an increase in $\mathrm{paO}_{2}$, indicating an increased functional residual capacity and/or alveolar recruitment. ${ }^{21-22}$ But high CPAP pressure was also associated with an increase in $\mathrm{paCO}_{2}$ due to an increase in dead space, alveolar overdistension, and a decrease in alveolar ventilation. ${ }^{21-23} \mathrm{nHFV}$ could be used to control $\mathrm{CO}_{2}$ retention and to permit the use of a higher Pâw pressure so as to reduce oxygen need.

Gaseous distension of the bowel has been mentioned as a disadvantage of the use of nasal CPAP in premature infants. This so-called CPAP belly syndrome has not been associated with necrotising enterocolitis or bowel obstruction and had a benign development. ${ }^{24}$

In our study some infants who were breathing room air still had clinically significant $\mathrm{CO}_{2}$ retention. In the alveolar air equation alveolar $\mathrm{pO}_{2}$ is determined by the inspiratory oxygen concentration minus the alveolar $\mathrm{pCO}_{2}$, divided by the respiratory exchange ratio. When an alveolar $\mathrm{pCO}_{2}$ is increased to, for example, $10 \mathrm{kPa}$ and the infant is breathing room air and has a respiratory exchange ratio of 0.8 , the alveolar $\mathrm{pO}_{2}$ will be $8.5 \mathrm{kPa}$. Assuming that the gradient between alveolar and arterial $\mathrm{pO}_{2}$ is not severely increased by atelectasis, scatter of ventilation perfusion ratios, or by the presence of a right to left shunt, a clinically significant hypercapnia can exist in association with a low but still normal and acceptable arterial $\mathrm{pO}_{2}$. In addition, as the $\mathrm{P} 90$ (the $\mathrm{paO}_{2}$ required for $90 \%$ oxygen saturation of haemoglobin) in preterm infants was reported to be $5.4(0.5)$ $\mathrm{kPa},{ }^{25}$ there is no clinical or physiological basis to increase the $\mathrm{PO}_{2}$ value when almost all haemoglobin is bound with oxygen.

In a heterogeneous group of infants with moderate respiratory diseases, $\mathrm{nHFV}$ was effective in reducing $\mathrm{pCO}_{2}$. nHFV might, therefore, be a valuable addition to the ventilatory management of the newborn infant, and might reduce the need for subsequent mechanical ventilation.

1 Hart SM, McNair M, Gasmu MR, et al. Pulmonary interstiial emphysema in very low birth weight infants. Arch Dis Child 1983;58:612-16.

2 Primhak RA. Factors associated with pulmonary air leak in premature infants receiving mechanical ventilation. $\mathcal{F}$ Pediatr 1983;102:764-8.

3 Bancalari E. Neonatal chronic lung disease. In: Fanaroff AA, Martin RJ. Neonatal-perinatal medicine. Diseases of the fetus and infant. St Louis: Mosby, 1997:1074-89.

4 Jacobsen T, Gronvall J, Petersen S, Andersen GE. Minitouch treatment of very low birth weight infants. Acta Paediatrica 1993;83:934-8.

5 Kamper J, Wulff K, Larsen C, Lindequist S. Early treatment with nasal continuous positive airway in very low birth with nasal continuous positive airway in very
weight infants. Acta Paediatrica $1993 ; 82: 193-7$.

6 Lundstrom KE. Initial treatment of premature infants: continuous positive airway pressure or ventilation? Eur $\mathcal{F}$ Pediatr 1996;155:S25-S9.

7 Verder H, Robertson B, Greisen G, et al. Surfactant therapy and nasal continuous positive airway pressure for newborns with respiratory distress syndrome. Danish-Swedish multicentre study group. $N$ Engl f Med 1994;331:1051-5.

8 So $\mathrm{BH}$, Tamura M, MIshina J, Watanabe T, Kamoshita S. Application of nasal continuous positive airway pressure to early extubation in very low birthweight infants. Arch Dis Child 1995;72:F191-F3.

9 Higgins RD, Richter SE, Davis JM. Nasal continuous positive airway pressure facilitates extubation of very low birth weight neonates. Pediatrics 1991;88:999-1003.

10 Tapia JL, Bancalari A, Gonzalez A, Mercado ME. Does continuous positive airway pressure (CPAP) during weaning from intermittent mandatory ventilation in very low birthweight infants have risks or benefits? A controlled birthweight infants have risks or be
trial. Pediatr Pulmonol 1995;5:269-74.

11 Chan V, Greenough A. Randomized trial of methods of extubation in acute and chronic respiratory distress. Arch Dis Child 1993;68:570-2.

12 Clark RH, Null DM. High-Frequency oscillatory ventilation. In: Pomerance JJ, Richardson CJ. eds. Neonatology for the clinician. Norwalk, CT: Appleton \& Lange, 1993:289309.

13 Clark RH. High-frequency ventilation. $f$ Pediatr 1994;124:661-70.

14 Wasunna A, Whitelaw AGL. Pulseoximetry in preterm infants. Arch Dis Child 1987;62:882-8.

15 Joint working group of the British Association of Perinatal Medicine and the Research Unit of the Royal College of Physicians. Development of audit measures and guidelines for good practice in the management of neonatal for good practice in the management of neonatal 1992;67:1221-7.

16 Boynton BR, Carlo WA. Pulmonary gasexchange during high-frequency ventilation. In: Boyton BR, Carlo WA, Jobe $\mathrm{AH}$, eds. New therapies for neonatal respiratory failure. A physiological approach. Cambridge: Cambridge University Press: 1994:218-44

17 Fredberg JJ. Summary: Pulmonary mechanics during high frequency ventilation. Acta Anesthesiol Scand 1989;33 $170-1$.

18 Chang HK. Mechanisms of gas transport during ventilation by high-frequency oscillation. f Appl Physiol 1984;56:55364.

19 Gittermann MK, Fusch C, Gittermann AR, Regazzoni BM, Moessinger AC. Early nasal continuous positive airway pressure treatment reduces the need for intubation in very pressure treatment reduces the need for intubation in very

20 Avery MA, Tooley WH, Keller JB, et al. Is chronic lung disease in low birth weight infants preventable? A survey of ease in low birth weight infants preven

21 Osher AB, Gothe B, Simmons DH, Waymost B, Green H. Effects of continuous positive airway pressure after oleic acid-induced lung injury in dogs. Pediatr Res 1978;9:9236.

22 Richardson CP, Jung AL. Effects of continuous positive airway pressure on pulmonary function and blood gases of infants with respiratory distress syndrome. Pediatr Res 1978;12:771-4

23 Bonta BW, Uauy R, Warshaw JB, Motoyama EK. Determination of optimal continuous positive pressure for the treatment of IRDS by measurement of esophageal pressure. F Pediatr 1977;91:449-54.

24 Jaille JC, Levin T, Wung JT, Abramson SJ, Ruzal-Shapiro C, Berdon WE. Benign gaseous distension of the bowel in premature infants treated with nasal continuous airway premature infants treated with nasal con
pressure. Am f Rheumatol 1992;158:125-7.

25 Émond D, Lachance C, Gagnon J, Bard H. Arterial partial pressure of oxygen required to achieve $90 \%$ saturation of hemoglobin in very low birth weight newborns. Pediatrics 1993;91:602-4 